\title{
¿

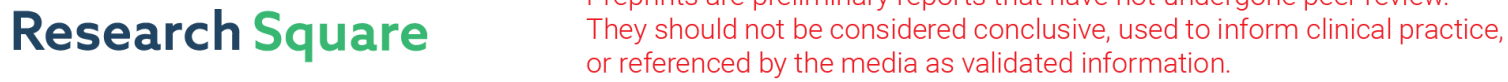 \\ Utilization of Facility-based Delivery Services in the Wa Municipality, Ghana
}

\section{Culbert Nuolabong}

Department of Epidemiology and Disease Control, School of Public Health, University of Ghana, Legon

\section{Kwadwo Owusu Akuffo}

Department of Optometry and Visual Science, College of Science, Kwame Nkrumah University of

Science and Technology, Kumasi

\section{Mukasa Kabiri}

Department of Disease Control and Epidemiology, College of Health and Well-being-Kintampo, Ministry of Health

\section{Priscillia Nortey}

Department of Epidemiology and Disease Control, School of Public Health, University of Ghana, Legon

\section{Ernest Tei Maya}

Department of Population, Family and Reproductive Health, School of Public Health, University of Ghana, Legon

\section{Isaiah Osei Duah Junior}

Department of Optometry and Visual Science, College of Science, Kwame Nkrumah University of Science and Technology, Kumasi

Anthony Danso-Appiah ( $\sim$ tdappiah01@gmail.com )

Department of Epidemiology and Disease Control, School of Public Health, University of Ghana, Legon

\section{Research Article}

Keywords: utilization, antenatal care, skilled delivery services, health facilities, maternal mortality ratio, Ghana

Posted Date: January 18th, 2022

DOI: https://doi.org/10.21203/rs.3.rs-1250026/v1

License: (c) (i) This work is licensed under a Creative Commons Attribution 4.0 International License. Read Full License 


\section{Abstract}

Background: Access to skilled delivery services are crucial in reducing maternal mortality, however, the prevalence of women with assisted deliveries in our health facilities remains low with reasonable disparities between rural and urban Ghana. This study examined the utilization of skilled delivery by pregnant women and its associated factors in the Wa Municipality of Ghana.

Methods: The study employed a community-based cross-sectional study. A simple random sampling was used to recruit two rural and two urban sub-districts and subsequently four communities selected from each of the respective sub-districts. Thirty-three eligible women of reproductive age (15- 49 years) who had delivered within the last one-year prior to the commencement of the study were selected from each community. A structured questionnaire was used to collate information on respondents sociodemographic, geographic and cultural factors that affect the utilization of skilled delivery services. Data was analyzed using Stata Statistical Software (version 12), frequencies and percentages were used to summarize data and associations between variables investigated with multiple regression analyses at a significance of $p<0.05$.

Results: Out of the 527 women interviewed, 481 (91.6\%) had a skilled delivery. Mothers were aged between 15 and 45 years with mean ( \pm SD) age of $26.4 \pm 9.4$ years. After statistical adjustment, rural residence (AOR=2.7, 95\% $\mathrm{Cl} 0.8-8.9, \mathrm{p}=0.036$ compared with urban residence), never attended antenatal care $(A O R=101,95 \% \mathrm{Cl} 10.2-1017, \mathrm{p}<0.001)$, health facility delivery $(A O R=0.1,95 \% \mathrm{Cl} 0.1-0.6$, $p<0.001)$, time taken to nearest health facility ( $\geq 31$ minutes $A O R=11.7,95 \% \mathrm{Cl} 3.6-38.6, p<0.001)$, and no Husband's consent (AOR=4.6, 95\% Cl $1.8-11.6, p<0.001)$ were significantly associated with uptake of skilled delivery services.

Conclusion: The findings of this study demonstrate adequate utilization of skilled delivery services among women in the Municipality. Efforts towards improvement of skilled delivery coverage should focus on health education, especially among rural women together with the expansion of healthcare services.

\section{Introduction}

Childbirth supervised by skilled birth attendants (SBAs: defined as persons proficiently trained to manage normal pregnancies, childbirth and the immediate postnatal period[1]) contributes to the quality of pregnancy and delivery outcomes. Delivery by SBAs has a positive impact by promoting early detection of complication during antenatal and/or postnatal care delivery and consequently reduction of maternal and neonatal morbidity and mortality [1]. In spite of several interventions targeted at improving maternal health globally, more than 500,000 women lose their lives during pregnancy and/or childbirth and with most of these mortalities concentrated in lower-and-middle income regions [2]. In particular, among the estimated annual maternal deaths, developing countries alone accounts for an estimated $99 \%$ and with more than two-thirds proportionate contribution from sub-Saharan Africa (SSA) [3]. 
According to the World Health Organization (WHO) inadequate utilization of skilled delivery services in SSA remains a major hindrance towards improving the health of reproductive women, especially during delivery[2, 3]. Mothers lifetime risk of death from pregnancy related conditions in this region stands at 1 in 38 compared to 1 in 3,700 in the advanced countries[4]. Consequently, unsafe delivery practices account for over $50 \%$ of maternal deaths in these developing countries $[5,6]$. Skilled health professionals are known to play a key role in the reduction of maternal mortality owing to their substantial contribution in prevention and management of pregnancy related complications, yet, a considerable higher number of women die due to delivery without skilled obstetric care[7].

Concurrently, institution other than home deliveries are considered save given the timely emergency medical care women received from skilled health professionals in unexpected complications and ultimately save their lives and that of their unborn babies. A systematic scoping review by Mekonnen et al. showed that most women within the sub-Saharan regions patronize home-based parturition other than conventional deliveries and this is ascribed to various individual, interpersonal, organizational and system level factors[2]. A case in point is Ghana where most women preferential utilization of home delivery are dictated by their educational background, cultural predilection, cheaper services, satisfaction of antenatal care services, tender nature of traditional birth attendants (TBAs) compared to orthodox health professionals as well as their closer proximity to TBAs other than health facilities[8-11].

Health system factors such as cost of services remains a significant barrier that continuously hamper most reproductive women from lower-and-middle income countries in seeking institution-based obstetric care[12]. In order to promote safe motherhood, various policies including no-fee-for-service, pay-for performance and voucher packages were implemented in most countries[13]. Exemplified in Ghana under the auspices of the Ministry of Health the National Health Insurance Scheme (NHIS) program was piloted in the northern parts of Ghana and fully operationalized across the entire country to provide maternal and pregnancy relieve packages to mothers $[14,15]$. However, the funding constraint of the NHIS program jeopardized most of the beneficial packages mothers received and with ensuing suboptimal facilityaccessed child delivery[14]. Similarly, maternal geographic and sociodemographic characteristics also influence attitudes towards seeking skilled attended child birth[9], however, the results are sparse[16]. Hence, a firm understanding of these dynamics are essential towards planning and formulation of robust maternal health policies.

The quarterly performance report of the Ghana Health Service revealed that of the seven maternal deaths reported in the Upper west region (one of the administrative region in country) five of the incidence occurred in the Wa Municipality the region's capital. In the same vein the upper west region weekly bulletin report showed a significantly higher MMR specifically 105 deaths per 100, 000 live births. Aside the alarming rate of this reports it also raises doubts on the strides made by the region towards attaining the target 3.1 of the SDG 3. Therefore, the overarching goal of this study was to assess the utilization of skilled delivery and its associated determinants among mothers in the Wa Municipality of the Upper West Region of Ghana. The outcome of this study will not only bring to fore the enabling and disenabling factors affecting skilled attended delivery by mothers but also help in formulating of strong policies to 
improve maternal health care more generally and consequently realizing the MMR target enshrined in SDG 3.

\section{Methods}

\section{Study design, population and setting}

A community-based cross-sectional study was conducted among a sample of mothers residing in 16 communities randomly selected from the Wa Municipality. The sample constituted women of reproductive age group (15- 49 years) who had delivered within the past one-year prior to the study. Respondents sociodemographic, socioeconomic, geographic and cultural characteristics that influence utilization of skilled delivery services were gathered with a pretested structured questionnaire. Among the eleven (11) districts in the upper west region Wa municipal is the solely considered municipality, with a total land area of about $1,078 \mathrm{~km}^{2}$, and shares boarders with Nadowli-Kaleo district to the north, Wa west district on south and on the west as well as the Wa east district towards the east. Wa doubles as both the municipal and the region's capital. The municipal is well-planned and with a serene atmosphere and adequate environmental sanitation [26]. The projected municipal population as of 2019 was estimated at 129,647 and with a growth rate of $1.7 \%$ per annum. The area is geographically partitioned into six subdistricts namely Wa Urban, Bamahu, Busa, Charia, Kanbali and Charigu and with Dagaaba and Sissalas as the predominant ethnic groups. The economic activities patronized by inhabitants within the area comprises of farming, trading, artisanship and government services. Most are peasant farmers and with a higher poverty rate and even worse among women given the patrilineal inheritance and male-dominated family head responsibilities. A significant majority are either Christians or Muslims and with a smaller fraction as traditionalist. The area serves as a home for six (6) Health Centers, three (3) Hospitals and Five (5) Clinics. The facilities together provide preventive therapies as well as specialized provisions including skilled service delivery. Maternal health services are generally poor in this locality.

\section{Inclusion/exclusion criteria}

The inclusion criteria encompassed mothers of infants one-year or older and had lived in the municipality for at least a year. In addition, women who visited the study site and satisfied the eligibility criteria was included, however women who failed to give a consent and/or had their child younger than a year were excluded.

\section{Sample size determination and sampling}

Considering the study area and to obtain a power not less than $50 \%$ a minimum sample size was computed using the Cochran single proportion formula $N=z^{2} p(1-p) / e^{2}$; where $n$ is the sample size; $z^{2}$ (abscissa of the normal curve that cuts an area of $\otimes$ at the tail or standard normal deviation at $95 \% \mathrm{Cl}$ ), $\mathrm{p}$ (proportion of skilled service delivery per study area) the This gives: 
$N=1.96^{2} \times 0.50(1-0.50) / 0.05^{2}=384.16$

With a design effect of 1.25 and a non-response rate of $10 \%$, a minimum total sample of 432 was obtained for the study. Further, the study employed a multistage cluster sampling afterwards to recruit participants. Specifically, based on a preexisting classification the study area was segregated into rural

and urban, the former constituted all sectors outside the Wa central district and vice versa. Subsequently, two urban and rural sub-districts clusters were respectively selected by simple random sampling. In the second stage, four communities were randomly selected from each of the four clusters. House numbers of all eligible households within the clusters were obtained on a written piece of papers, shuffled in an opaque envelope and subsequently a household chosen at random. Of the 33 randomly households a single mother was recruited from each and instances where multiple mothers in a particular household met the study inclusion criteria balloting was applied in selection.

\section{Quality Control}

A standardized questionnaire was prepared in English and translated into the local dialect (Dagaare and Sissali) for easy comprehension. The translated questionnaire was pretested in a the Kpesiri community a local vicinity within the municipality and subsequently modified to ensure logical flow and understanding before final administration in the field survey. Well-trained professional nurses were recruited for data collection and with all necessary procedures performed under a stringent of the supervision of the principal investigator

\section{Data collection and management}

The data were collected from January 13, 2015 to May 31, 2015 using structured pre-tested questionnaire. The questionnaire asked questions on women's social and demographic characteristics including age, education, marital status, occupation, ethnicity, religion, occupation and place of birth; cultural and geographical barriers namely antenatal visits during last pregnancy, place of delivery, time taken to the nearest health facility, requires husband consent on place of delivery, consequences for not seeking husband's consent and utilization of health facility delivery. The questionnaire was administered by trained interviewers (Professional Nurses) who frequent supervision during the data collection. The questionnaires were checked after the interviews

\section{Data analysis}

Data were entered into Statistical Package and Service Solution (SPSS) Software version 16 cleaned and doubled checked for multiple entries. Single entry dataset was transferred into STATA Software version 12 (Stata Corp, Texas, USA) for formal analysis. Univariate analysis was performed and presented as frequencies and percentages. Proportionate distribution of skilled delivery services across demographic 
characteristics was tested with Pearson chi-square statistics at $p<0.05$. Binary and multiple logistic regression analyses were used to investigate factors significantly associated with the outcome variable of skilled delivery. Odds ratios and corresponding confidence intervals were presented.

\section{Results}

\section{Sociodemographic characteristic of birth mothers}

Though we set out to recruit a minimum of 384 birth mothers, the study sampled 528 subjects with mean age of mean age of $26.4 \pm 9.4$ years. Majority (41.0\%) were within the age range of 25-29, had received no formal education (45.5\%) were married (91.3\%) and resided in a rural area (60.8\%). Most belonged to the Dagaba ethnic group (87.9\%) were Muslim (56.8\%), and with a considerable majority engaged in farming as their main occupation (28.2\%). A greater proportion of mothers gave birth at a health facility $(91.5 \%)$ compared with a smaller minority that delivered at homes and/or received traditional birth attendants' services (8.5\%) as shown in Table 1. 
Table 1: Sociodemographic characteristics of birth mothers $(n=528)$

\begin{tabular}{|c|c|c|}
\hline Variable & Frequency & Percent \\
\hline \multicolumn{3}{|l|}{ Age } \\
\hline $15-19$ & 30 & 5.7 \\
\hline $20-24$ & 172 & 32.6 \\
\hline $25-29$ & 216 & 41 \\
\hline $30-34$ & 81 & 15.3 \\
\hline$\geq 35$ & 29 & 5.5 \\
\hline \multicolumn{3}{|l|}{ Level of education } \\
\hline None & 240 & 45.5 \\
\hline Primary & 87 & 16.5 \\
\hline Junior High School & 113 & 21.4 \\
\hline Senior High School & 59 & 11.2 \\
\hline Tertiary & 29 & 5.5 \\
\hline \multicolumn{3}{|l|}{ Marital status } \\
\hline Single & 30 & 5.7 \\
\hline Married & 482 & 91.3 \\
\hline Divorced/widow & 16 & 3 \\
\hline \multicolumn{3}{|l|}{ Residence } \\
\hline Urban & 207 & 39.2 \\
\hline Rural & 321 & 60.8 \\
\hline \multicolumn{3}{|l|}{ Ethnicity } \\
\hline Dagaaba & 464 & 87.9 \\
\hline Sissala & 55 & 10.4 \\
\hline Other & 9 & 1.7 \\
\hline \multicolumn{3}{|l|}{ Religion } \\
\hline Christian & 221 & 41.9 \\
\hline Muslim & 300 & 56.8 \\
\hline Traditional & 6 & 1.1 \\
\hline
\end{tabular}




\begin{tabular}{lll} 
Other & 1 & 0.2 \\
\hline Occupation & 149 & \\
\hline Farming & 123 & 28.2 \\
\hline Trading & 70 & 23.3 \\
\hline Housewife Only & 120 & 13.3 \\
\hline Seamstress & 27 & 22.7 \\
\hline Public Servant & 39 & 5.1 \\
\hline Other & & 7.4 \\
\hline Place of delivery ${ }^{\ddagger}$ & 45 & 8.5 \\
\hline Home/TBAs & 483 & 91.5 \\
\hline Health facility & & \\
\hline †BAs, Traditional birth attendants & & \\
\hline
\end{tabular}

\section{Sociodemographic factors related to type of delivery}

Table 2 presents on the distribution of sociodemographic characteristics across the type of delivery.

There was a significant variation among participant's level of education, respondent's residence, religion, respondent's occupation and husband's occupation in relation to the type of delivery ( $p<0.05$ for all) as shown in Table 2. 
Table 2: Sociodemographic characteristics related to type of delivery

Predictor variables Type of delivery $(n=528)$

$\begin{array}{llll}\begin{array}{l}\text { Number of Skilled } \\ \text { delivery }\end{array} \quad \text { Percent } & \begin{array}{l}\text { Number of Unskilled } \\ \text { delivery }\end{array} & \text { Percent } & \begin{array}{l}p \text { - } \\ \text { value }\end{array}\end{array}$

Age of mother

\begin{tabular}{|c|c|c|c|c|c|}
\hline $15-19$ & 26 & 86.7 & 4 & 13.3 & 0.252 \\
\hline $20-24$ & 156 & 90.7 & 16 & 9.3 & \\
\hline $25-29$ & 200 & 92.6 & 16 & 7.4 & \\
\hline $30-34$ & 76 & 93.8 & 5 & 6.2 & \\
\hline$\geq 35$ & 23 & 79.3 & 6 & 20.7 & \\
\hline \multicolumn{6}{|l|}{ Level of education } \\
\hline None & 211 & 87.9 & 29 & 12.1 & 0.014 \\
\hline Primary & 78 & 89.7 & 9 & 10.3 & \\
\hline Junior high school & 109 & 96.4 & 4 & 3.6 & \\
\hline Senior high school & 56 & 94.9 & 3 & 5.1 & \\
\hline Tertiary & 29 & 100.0 & 0 & 0.0 & \\
\hline \multicolumn{6}{|l|}{ Marital status } \\
\hline Single & 29 & 96.7 & 1 & 3.3 & 0.291 \\
\hline Married & 439 & 91.1 & 43 & 8.9 & \\
\hline Divorced/widow & 16 & 100.0 & 0 & 0.0 & \\
\hline \multicolumn{6}{|l|}{ Residence } \\
\hline Urban & 202 & 97.6 & 5 & 2.4 & 0.001 \\
\hline Rural & 283 & 88.2 & 38 & 11.8 & \\
\hline
\end{tabular}

Ethnicity

\begin{tabular}{llllll} 
Dagaaba & 423 & 91.2 & 41 & 8.8 & 0.584 \\
\hline Sissala & 52 & 94.5 & 3 & 5.5 & \\
\hline Other & 9 & 100.0 & 0 & 0.0
\end{tabular}

Religion

Christian

91.4

19

8.6

0.001

Muslim

92.3

23

7.7 


\begin{tabular}{|c|c|c|c|c|c|}
\hline Traditional & 2 & 33.3 & 4 & 66.7 & \\
\hline Other & 1 & 100.0 & 0 & 0.0 & \\
\hline \multicolumn{6}{|l|}{ Occupation } \\
\hline Farming & 127 & 85.2 & 22 & 14.8 & 0.002 \\
\hline Trading & 117 & 95.9 & 6 & 4.1 & \\
\hline Housewife Only & 60 & 85.7 & 10 & 14.3 & \\
\hline Seamstress & 113 & 94.2 & 7 & 5.8 & \\
\hline Public Servant & 26 & 96.3 & 1 & 3.7 & \\
\hline Other & 39 & 100.0 & 0 & 0.0 & \\
\hline \multicolumn{6}{|l|}{$\begin{array}{l}\text { Husband's } \\
\text { occupation }\end{array}$} \\
\hline Farming & 169 & 86.2 & 27 & 13.8 & 0.027 \\
\hline Trading & 71 & 91.0 & 7 & 9.0 & \\
\hline Artisan & 138 & 95.2 & 7 & 4.8 & \\
\hline Tailor & 20 & 95.2 & 1 & 4.8 & \\
\hline Public Servant & 75 & 96.2 & 3 & 3.8 & \\
\hline Other & 10 & 100.0 & 0 & 0.0 & \\
\hline
\end{tabular}

\section{Sociocultural and geographic factors related to type of delivery}

Table 3 presents the socio-cultural and geographical factors associated with skilled delivery among participants. All factors: antenatal attendance, choice of place of delivery, time taken to reach nearest health facility, seeking husband consent before deciding where to deliver and the consequences for not seeking husband's consent were significantly associated with type of delivery $(p<0.05)$. 
Table 3: Sociocultural and geographic factors related to type of delivery

Predictor variables

Frequency Type of delivery

$\begin{array}{llll}\begin{array}{l}\text { Skilled } \\ \text { delivery }\end{array} \quad \text { Percent } & \begin{array}{l}\text { Unskilled } \\ \text { delivery }\end{array} & \text { Percent } & \begin{array}{l}\mathrm{p} \text { - } \\ \text { value }\end{array}\end{array}$

Antenatal visit during last pregnancy

$\begin{array}{lllllll}\text { Attended antenatal care } & 514 & 474 & 92.2 & 40 & 7.8 & 0.001 \\ \begin{array}{l}\text { Never attended antenatal } \\ \text { care }\end{array} & 14 & 6 & 42.9 & 8 & 57.1 & \end{array}$

Where would you prefer to

deliver

$\begin{array}{lllllll}\text { Home delivery } & 12 & 5 & 41.7 & 7 & 58.3 & 0.001 \\ \text { Health facility delivery } & 516 & 475 & 92.1 & 41 & 7.9 & \end{array}$

Time to nearest health

facility

\begin{tabular}{lllllll}
$\leq 10$ minutes & 180 & 167 & 92.8 & 13 & 7.2 & 0.001 \\
\hline $11-30$ minutes & 298 & 280 & 94.3 & 17 & 5.7 & \\
$>30$ minutes & 50 & 33 & 66.0 & 17 & 34.0
\end{tabular}

Needing husband's consent on place of delivery

\begin{tabular}{lllllll}
\hline Yes & 421 & 396 & 94.1 & 25 & 5.9 & 0.001 \\
\hline No & 100 & 80 & 80.0 & 20 & 20.0 & \\
\hline Others & 7 & 7 & 100.0 & 0 & 0.0 & \\
\hline
\end{tabular}

Consequence of not seeking consent from husband

\begin{tabular}{lllllll}
$\begin{array}{l}\text { My husband will punish } \\
\text { me }\end{array}$ & 9 & 6 & 66.7 & 3 & 33.3 & 0.004 \\
\hline Gods will punish me & 28 & 23 & 82.1 & 5 & 17.9 \\
\hline Elders will punish me & 484 & 447 & 92.5 & 36 & 7.5 \\
\hline Others & 7 & 7 & 100.0 & 0 & 0.0
\end{tabular}

Factors associated with uptake of skilled delivery among participants

The bivariate logistic regression analysis (Table 4) showed that Junior secondary school education (COR=0.3, 95\% Cl $0.1-0.8, p=0.016$ compared with no formal education), rural residence (COR $=5.4,95 \%$ $\mathrm{Cl} 2.1-13.9, p=0.001$ compared with urban residence), traditional religion (COR=15.9, 95\% $\mathrm{Cl} 2.5-100$, $\mathrm{p}=0.003$ compared with Christian religion), respondent's occupation (compared with farming: trading 
COR=0.3, 95\% Cl 0.1 - 0.7, p=0.006; seamstress COR=0.4, 95\% Cl $0.1-0.9, p=0.023)$, Husband's occupation (compared with farming: Artisan $\mathrm{COR}=0.6,95 \% \mathrm{Cl} 0.3-0.8, \mathrm{p}=0.009$; Public Servant COR=0.3, $95 \% \mathrm{Cl} 0.1-0.8, \mathrm{p}=0.027)$, never attended antenatal care (COR=14.4, 95\% Cl $4.6-44.6, \mathrm{p}<0.001)$, place of delivery (Health facility COR=0.1,95\% Cl $0.1-0.3, p<0.001$ compared with Home/TBA), time taken to nearest health facility ( $\geq 31$ minutes $\mathrm{COR}=5.4,95 \% \mathrm{Cl} 2.3-12.6, \mathrm{p}<0.001$ compared with $\leq 10$ minutes), no Husband's consent (COR=4.0,95\% Cl $2.1-7.5, p<0.001)$, and consequences of not seeking consent from Husband (elders will punish me $\mathrm{COR}=0.2,95 \% \mathrm{Cl} 0.1-0.7, \mathrm{p}=0.012$ compared with my husband will punish me) were all significantly associated with uptake of skilled delivery services. Further, in the multiple logistic regression model, rural residence $(A O R=2.7,95 \% \mathrm{Cl} 0.8-8.9, \mathrm{p}=0.036$ compared with urban residence), never attended antenatal care (AOR=101, 95\% $\mathrm{Cl} 10.2-1017, p<0.001)$, place of delivery (Health facility AOR=0.1, 95\% $\mathrm{Cl} 0.1-0.6, p<0.001$ compared with Home/TBA), time taken to nearest health facility ( $\geq 31$ minutes $A O R=11.7,95 \% \mathrm{Cl} 3.6-38.6, p<0.001$ compared with $\leq 10$ minutes), and no husband's consent (AOR=4.6, 95\% $\mathrm{Cl} 1.8-11.6, p<0.001)$ were all significantly associated with uptake of skilled delivery services. 
Table 4: Bivariate and multiple logistic regression of factors associated with uptake of skilled delivery services

Predictor variables Frequency COR AOR $95 \% \mathrm{Cl} \quad$-value

Level of education

None
Primary
Junior high school

Senior high school

Tertiary

240 Ref Ref

Residence

Urban

Rural

Religion

Christian

Muslim

Traditional

Other

87

0.8

0.8

$0.2-2.3$

0.119

113

0.3

59

0.3

0.3

0.1-1.3

29

\section{Occupation}

Farming

Trading

Housewife Only

Seamstress

Public Servant

Other

$\begin{array}{lllll}207 & \text { Ref } & \text { Ref } & & \\ 321 & 5.4 & 2.7 & 0.8-8.9 & 0.036\end{array}$

221 Ref Ref

300

0.9

0.7

$0.3-1.8$

0.341

6

$15.9 \quad 0.3$

0.1-100.3

1

Husband's occupation

\begin{tabular}{lccccc} 
Farming & 197 & Ref & Ref & & \\
\hline Trading & 78 & 0.6 & 1.1 & $0.3-3.8$ & 0.774 \\
\hline Artisan & 145 & 0.3 & 0.6 & $0.2-2.1$ & \\
\hline Tailor & 21 & 0.3 & 0.5 & $0.1-8.6$ & \\
Public Servant & 78 & 0.3 & 1.5 & $0.3-9.0$ &
\end{tabular}


Antenatal visit during last pregnancy

Attended antenatal

514

Ref Ref

Never attended antenatal

14

$14.4 \quad 101$

$10.2-1017<0.001^{\star}$

Time taken to nearest health facility

$\leq 10$ minutes

$11-30$ minutes

$>30$ minutes

Needing husband's consent on place of delivery

Yes

No

Other
Ref Ref

$\begin{array}{llll}0.8 & 1.1 & 0.5-2.9 & <0.001^{*}\end{array}$

$5.4 \quad 11.7 \quad 3.6-38.6$

COR, Crude Odds Ratio; AOR, Adjusted Odds Ratio; Cl, Confidence Interval; Ref, Reference; Bivariate logistic regression analysis - Wald test $p<0.02$ was enrolled in the multivariate model at a significance of $\mathrm{p} \leq 0.05$.

\section{Discussion}

This study investigated the utilization of facility delivery services and associated factors among birth mothers in the Wa Municipality in the Upper West region of Ghana. The study observed that over $90 \%$ of study respondents had taken up skilled delivery services. After statistical adjustment the factors associated with uptake of skilled delivery services included rural residence, lack of antenatal care attendance, takes more than 30 minutes to get to nearest health facility and not requiring the consent of the husband before deciding the place of delivery.

The high proportions of skilled deliveries observed in this study are comparable to findings from previous investigations in Ghana [10,11, 17], Ethiopia[18], Kenya[19, 20] and Tanzania[21] but contrast with previous study by Ameyaw et al. that showed a lower prevalence of accessed skilled obstetric care among women from Niger, Mali, and Sierra Leone and with ranges of $32.5 \%$ to $45.2 \%[22]$. Generally, skilled birth attendance in East Africa[22-24] and parts of the South-Asian regions [25-27] remains low as compared to Ghana $[9,10]$.

The high level of utilization of skilled deliveries in the Municipality could partly be attributed to the increased number of Community based Health and Planning Services (CHPS) compounds and Community Health Officers ( $\mathrm{CHO})$ in the study area. The CHPS concept encourages health care services to be brought to the doorsteps of the people by deploying health personnel to reside in the community 
and provide basic clinically, preventive obstetric care for local people. In particular, in the community, nurses provide regular home visits to educate and engage community leaders to support health care policies and own the health services which could have contributed to women's uptake of skilled attendant delivery. This policy increases access and availability of health services including antenatal and child delivery services. Given that almost all the women both irrespective of geographic residence preferred to deliver with a skilled attendant in health facilities could be attributed to positive influence from $\mathrm{CHO}$ nurses and midwives in the areas[28]. However, there is still the need for more sensitization since about $10 \%$ of the women reported that they delivered at home and were attended to by TBAs. A study conducted in three districts in Upper East Region with a similar prevalence of $80 \%$ skilled delivery uptake explained that the availability of CHPS services, equipment and logistics would stimulate staff with the requisite training and skills to better perform, improve on the quality of services and thereby attracting more women to use skilled services[29] This finding suggests that women make good use of skilled delivery services and place value on the role of health institutions in maternal care.

Women in rural area were more likely to deliver at home compared to their urban counterparts. This finding agrees with a similar study conducted in Kenya where it was reported that rural women were less likely to seek skilled delivery care services compared to their urban counterparts even after controlling for education and wealth[30]. The variations in the patterns of evidence could be attributed to the fact that women in urban areas easily accessed facility-based services with minimal distance travelled, make adequate decisions regarding place of birth, possessed in-depth knowledge on pregnancy and delivery complications, and better accessed health information compared to their rural counterparts.

Improved access to health care services through the provision of both private and public health facilities in the towns and increase in number of skilled health professionals (such as midwives) in urban areas could be one of the factors responsible for the high proportions of deliveries by skilled attendant reported in this study. Similarly, the 2012 Ghana Demographic and Health Survey identified urban inhabitants to show greater preference towards facility-based child delivery compared to the rural dwelling counterparts[31]. Improvement in health infrastructure, health worker motivation and provision of better conditions of service among health personnel in rural areas especially in those in existing CHPS compounds could motivate other skilled health personnel to embrace transfers to such areas.

Consequently, the ensuing effect could pose a direct positive bearing on quality health services including maternal child delivery services and ultimately bridge the existing maternal health disparities within the Municipality.

Patronage of unskilled and/or home delivery services among mothers are closely linked with the distance they would travelled in accessing facility-based healthcare services[11, 21, 32, 33]. In this study distance was associated with health facility delivery with increased odd of receiving obstetric care at home since some women must have to travel more than 30 minutes by foot before they could access a nearest health facility. Consistent with previous investigations in Ghana, distance has been reported as a major setback that compromises on health accessing facility delivery[10,11, 21, 32]. Though access to skilled delivery services has been improved over the years with the introduction of the CHPS concepts to bring 
health care to the door steps of the community much is expected especially in many rural areas where access to skilled delivery services is inadequate, poor road network and poor transportation system is a major challenge. The current study established that women in the Wa municipality who resided in rural areas are twice less likely to access skilled delivery services compared to urban compatriots

The study also revealed antenatal care attendance as a significant determinant of accessing skilled delivery services. Our finding corroborates with similar studies from Ethiopia[34-36] and Nepal[3739] which showed an increased tendency towards institutional accessed delivery following antenatal

visits. We observed partner's support as a significant determinant with positive influence on seeking facility-based delivery and this corroborates with previous reports[40-42]. Furthermore, although women autonomy in decision making have a positive influence on seeking institutional child delivery[43], yet in some parts of northern Ghana where families are headed by males, the decision of place of delivery is the exclusive duty of the husband[42]. Therefore, engagement of men in maternal health education is essential and could improve women access to skilled delivery more generally.

\section{Limitations and strengths of the study}

Our study has some limitations worth mentioning. First, the cross-sectional nature of the study restricted researchers in identifying causal associations. In addition, considering that the study utilized a quantitative other than mixed methods any possible mother and health workers interactions could not be elicited. Another drawback of the study was that the participants self- reported information on previous pregnancies might be subject to recall bias. Again, another limitation was that the study sampled women from Wa municipality and could not generalize its findings to the entire Upper West region of Ghana. Health system factors as well as the roles of husbands and family relatives, which could possibly influence utilization of Skilled Births Attendants services were beyond the scope of the study and therefore could be a focus for future investigations. However, given the community-based approach to this study our findings could reflects the actual experience of mothers within the Wa municipality.

\section{Conclusion}

The findings from this study demonstrate adequate utilization of skilled delivery services among women in the Wa municipality. Determinants of uptake of skilled delivery services were rural residence, lack of antenatal care attendance, health facility delivery, time taken to reach nearest health facility and absence of husband's consent. Husbands, household heads and individuals with impoverished and low educational backgrounds should be targeted in rural areas through behavioral change communication and/or information, education and communication models to promote safe motherhood, together with healthy reproductive life among women in the region. Mass media campaigns should be conducted to highlight the cons of traditional child deliver practices and benefits of the utilization of skilled maternal care services and. The study offers the needed information for policy and improvement of quality of child delivery services across the region. 


\section{Abbreviations}

AOR, Adjusted Odds Ratio; CHPS; Community based Health and Planning Services; CHO, Community Health Officer; Cl, Confidence Interval; SDGs, Sustainable Development Goals; $\mathrm{MOH}$, Ministry of Health; NHIS, National Health Insurance Scheme; SSA, Sub-Saharan Africa; SD, Standard deviation; SPSS, Statistical Package and Service Solution; TBA; Traditional Birth Attendant; WHO, World Health Organization

\section{Declarations}

\section{Acknowledgement}

We thank the Regional Health Directorate and Municipal Health Directorate for their support in completing this study.

\section{Authors contributions}

The authors' contribution was as follows; Conceptualization, $\mathrm{CN}$, and ADA; methodology, CN, MK, PN, ETM, and ADA; formal analysis, CN, MK, ETM; writing original draft-preparation, CN, KOA, MK, PN, ETM, IODJ, and ADA; writing-review and editing, FD, KOA, MK, PN, ETM, IODJ, and ADA; supervision of the study, ADA. All authors read and approved the manuscript.

\section{Ethics approval and consent to participate}

Ethical approval was obtained from the Ethical Review Board of the Ghana Health Service (reference number GHS - ERC: 123/02/15). Permission and subsequent approval was sought and approved from Upper West Regional Health Directorate and Wa Municipal Health Administration. All the mothers gave their consent prior to their inclusion in the study. Participation was completely voluntary.

\section{Consent for publication}

Not applicable

\section{Availability of data and materials}

The datasets generated during and/or analyzed during the current study are included in this published article.

\section{Competing interest}

The authors declare no competing interest.

\section{Funding}


The research received no specific grant from any funding agency in the public, commercial, or not-forprofit sectors.

\section{References}

1. W.H.O: Making pregnancy safer: the critical role of the skilled attendant: A joint statement by WHO, ICM and

FIGO. https://www.who.int/reproductivehealth/publications/maternal_perinatal_health/9241591692/en/. 2004.

2. Mekonnen T, Dune T, Perz J: Maternal health service utilisation of adolescent women in subSaharan Africa: a systematic scoping review. BMC Pregnancy Childbirth 2019, 19(1):366.

3. Pearson L, Larsson M, Fauveau V, Standley J: Childbirth care. file:///C:/Users/GODGIV 1/AppData/Local/Temp/aonsectionIII_3-1.pdf. 2021.

4. Garenne M, McCaa R: Maternal mortality for 181 countries, 1980-2008. Lancet 2010, 376(9750):1389.

5. Bhandari TR, Kutty VR, Sarma PS, Dangal G: Safe delivery care practices in western Nepal: Does women's autonomy influence the utilization of skilled care at birth? PLoS One 2017, 12(8):e0182485.

6. Ononokpono DN, Odimegwu CO: Determinants of Maternal Health Care Utilization in Nigeria: a multilevel approach. Pan Afr Med J 2014, 17 Suppl 1:2.

7. Chavane LA, Bailey P, Loquiha $O$, Dgedge $M$, Aerts $M$, Temmerman M: Maternal death and delays in accessing emergency obstetric care in Mozambique. BMC Pregnancy Childbirth 2018, 18(1):71.

8. Allou L: Factors influencing the utilization of TBA services by women in the Tolon district of the northern region of Ghana. Scientific African 2018.

9. Manyeh AK, Akpakli DE, Kukula V, Ekey RA, Narh-Bana S, Adjei A, Gyapong M: Socio-demographic determinants of skilled birth attendant at delivery in rural southern Ghana. BMC Res Notes 2017, 10(1):268.

10. Gudu W, Addo B: Factors associated with utilization of skilled service delivery among women in rural Northern Ghana: a cross sectional study. BMC Pregnancy Childbirth 2017, 17(1):159.

11. Saaka M, Akuamoah-Boateng J: Prevalence and Determinants of Rural-Urban Utilization of Skilled Delivery Services in Northern Ghana. Scientifica (Cairo) 2020, 2020:9373476.

12. Banke-Thomas A, Ayomoh Fl, Abejirinde IO, Banke-Thomas O, Eboreime EA, Ameh CA: Cost of Utilising Maternal Health Services in Low- and Middle-Income Countries: A Systematic Review. Int J Health Policy Manag 2020. 
13. Vargas $\mathrm{V}$, Ahmed S, Adams AM: Factors enabling comprehensive maternal health services in the benefits package of emerging financing schemes: A cross-sectional analysis from 1990 to 2014. PLOS One 2018, 13(9):e0201398.

14. Singh K, Osei-Akoto I, Otchere F, Sodzi-Tettey S, Barrington C, Huang C, Fordham C, Speizer I: Ghana's National Health insurance scheme and maternal and child health: a mixed methods study. BMC Health Serv Res 2015, 15:108.

15. Koduah A, van Dijk H, Agyepong IA: The role of policy actors and contextual factors in policy agenda setting and formulation: maternal fee exemption policies in Ghana over four and a half decades. Health Res Policy Syst 2015, 13:27.

16. Afful-Mensah G N-AE, Boakye-Yiadom L.: Rural-urban differences in the utilization of maternal healthcare in Ghana: the case of antenatal and delivery services. Int J Food Sci 2021, 2021:6415620.

17. Nuamah GB, Agyei-Baffour P, Mensah KA, Boateng D, Quansah DY, Dobin D, Addai-Donkor K: Access and utilization of maternal healthcare in a rural district in the forest belt of Ghana. $B M C$ Pregnancy Childbirth 2019, 19(1):6.

18. Abebe HT, Adhana MT, Gebremichael MW, Gezae KE, Gebreslassie AA: Magnitude, trends and determinants of skilled delivery from Kilite-Awlaelo Health Demographic Surveillance System, Northern Ethiopia, 2009- 2017. PLoS One 2021, 16(9):e0254146.

19. Nyongesa C, Xu X, Hall JJ, Macharia WM, Yego F, Hall B: Factors influencing choice of skilled birth attendance at ANC: evidence from the Kenya demographic health survey. BMC Pregnancy

Childbirth 2018, 18(1):88.

20. Gitonga E, Muiruri F: Determinants of health facility delivery among women in Tharaka Nithi county, Kenya. Pan Afr Med J 2016, 25(Suppl 2):9.

21. Damian DJ, Tibelerwa JY, John B, Philemon R, Mahande MJ, Msuya SE: Factors influencing utilization of skilled birth attendant during childbirth in the Southern highlands, Tanzania: a multilevel analysis. BMC Pregnancy Childbirth 2020, 20(1):420.

22. Ameyaw EK, Dickson KS: Skilled birth attendance in Sierra Leone, Niger, and Mali: analysis of demographic and health surveys. BMC Public Health 2020, 20(1):164.

23. Mwangi W, Gachuno O, Desai M, Obor D, Were V, Odhiambo F, Nyaguara A, Laserson KF: Uptake of skilled attendance along the continuum of care in rural Western Kenya: selected analysis from Global Health initiative survey-2012. BMC Pregnancy Childbirth 2018, 18(1):175.

24. Cotter $\mathrm{K}$, Hawken $\mathrm{M}$, Temmerman M: Low use of skilled attendants' delivery services in rural Kenya. J Health Popul Nutr 2006, 24(4):467-471. 
25. Joseph G, da Silva IC, Wehrmeister FC, Barros AJ, Victora CG: Inequalities in the coverage of place of delivery and skilled birth attendance: analyses of cross-sectional surveys in $\mathbf{8 0}$ low and middle-income countries. Reprod Health 2016, 13(1):77.

26. Rahman MA, Rahman MA, Rawal LB, Paudel M, Howlader MH, Khan B, Siddiquee T, Rahman A, Sarkar A, Rahman MS et al: Factors influencing place of delivery: Evidence from three south-Asian countries. PLoS One 2021, 16(4):e0250012.

27. Choulagai B, Onta S, Subedi N, Mehata S, Bhandari GP, Poudyal A, Shrestha B, Mathai M, Petzold $M$, Krettek A: Barriers to using skilled birth attendants' services in mid- and far-western Nepal: a crosssectional study. BMC Int Health Hum Rights 2013, 13:49.

28. Johnson FA, Frempong-Ainguah F, Matthews Z, Harfoot AJ, Nyarko P, Baschieri A, Gething PW, Falkingham J, Atkinson PM: Evaluating the impact of the community-based health planning and services initiative on uptake of skilled birth care in Ghana. PLoS One 2015, 10(3):e0120556.

29. Apanga PA, Awoonor-Williams JK: Maternal Death in Rural Ghana: A Case Study in the Upper East Region of Ghana. Front Public Health 2018, 6:101.

30. Kitui J, Lewis S, Davey G: Factors influencing place of delivery for women in Kenya: an analysis of the Kenya demographic and health survey, 2008/2009. BMC Pregnancy Childbirth 2013, 13:40.

31. Ghana Statistical Service (GSS), Ghana Health Service (GHS), and ICF International. 2015. Ghana Demographic and Health Survey 2014. Rockville, Maryland, USA: GSS, GHS, and ICF International.

32. Dotse-Gborgbortsi W, Dwomoh D, Alegana V, Hill A, Tatem AJ, Wright J: The influence of distance and quality on utilisation of birthing services at health facilities in Eastern Region, Ghana. BMJ Glob Health 2019, 4(Suppl 5):e002020.

33. Alemayehu M, Mekonnen W: The Prevalence of Skilled Birth Attendant Utilization and Its Correlates in North West Ethiopia. Biomed Res Int 2015, 2015:436938.

34. Wilunda C, Quaglio G, Putoto G, Takahashi R, Calia F, Abebe D, Manenti F, Dalla Riva D, Betran AP, Atzori A: Determinants of utilisation of antenatal care and skilled birth attendant at delivery in South West Shoa Zone, Ethiopia: a cross sectional study. Reprod Health 2015, 12:74.

35. Umer A, Zinsstag J, Schelling E, Tschopp R, Hattendof J, Osman K, Yuya M, Ame A, Zemp E: Antenatal care and skilled delivery service utilisation in Somali pastoral communities of Eastern Ethiopia. Trop Med Int Health 2020, 25(3):328-337.

36. Fekadu GA, Kassa GM, Berhe AK, Muche AA, Katiso NA: The effect of antenatal care on use of institutional delivery service and postnatal care in Ethiopia: a systematic review and meta-analysis. $B M C$ Health Serv Res 2018, 18(1):577. 
37. Sharma SR, Poudyal AK, Devkota BM, Singh S: Factors associated with place of delivery in rural Nepal. BMC Public Health 2014, 14:306.

38. Karkee R, Binns CW, Lee AH: Determinants of facility delivery after implementation of safer mother programme in Nepal: a prospective cohort study. BMC Pregnancy Childbirth 2013, 13:193.

39. Karkee R, Lee AH, Binns CW: Birth preparedness and skilled attendance at birth in Nepal: implications for achieving millennium development goal 5. Midwifery 2013, 29(10):1206-1210.

40. Teklesilasie W, Deressa W: Husbands' involvement in antenatal care and its association with women's utilization of skilled birth attendants in Sidama zone, Ethiopia: a prospective cohort study. BMC Pregnancy Childbirth 2018, 18(1):315.

41. Greenspan JA, Chebet JJ, Mpembeni R, Mosha I, Mpunga M, Winch PJ, Killewo J, Baqui AH, McMahon SA: Men's roles in care seeking for maternal and newborn health: a qualitative study applying the three delays model to male involvement in Morogoro Region, Tanzania. BMC Pregnancy Childbirth 2019, 19(1):293.

42. Ganle JK, Kombet ML, Baatiema L: Factors influencing the use of supervised delivery services in Garu-Tempane District, Ghana. BMC Pregnancy Childbirth 2019, 19(1):141.

43. Speizer IS, Story WT, Singh K: Factors associated with institutional delivery in Ghana: the role of decision-making autonomy and community norms. BMC Pregnancy Childbirth 2014, 14:398. 